Juanita K. Hodax ${ }^{a}$, Kimberly Bowerman ${ }^{\mathrm{a}}$ and Jose Bernardo Quintos*

\title{
Benign thyroid nodules in pediatric patients: determining best practices for repeat ultrasound evaluations
}

https://doi.org/10.1515/jpem-2018-0476

Received November 1, 2018; accepted June 13, 2019; previously published online July 4, 2019

\begin{abstract}
Background: The American Thyroid Association (ATA) recommendations for the follow-up of thyroid nodules with benign fine needle aspiration (FNA) cytology in children are largely based on adult data, despite well-characterized differences between thyroid nodules in adults and children. We aimed to determine the optimal time interval for repeat evaluation of an FNA-benign thyroid nodule in a pediatric patient.
\end{abstract}

Methods: This is a retrospective chart review of patients $<19$ years of age from 2003 to 2013 with a benign thyroid nodule by FNA cytology.

Results: We identified 43 patients with benign thyroid nodule cytology on FNA. The average age at diagnosis was 15.6 years, with female predominance (91\%). Initial ultrasound (US) findings showed an average nodule size of $2.5 \mathrm{~cm}, 10 \%$ with calcifications, 37\% hyperemia, 29\% hypoechogenicity and 7\% lymphadenopathy. Follow-up US was done in $42 \%$. The first follow-up US occurred on average at 15 months after the initial US. Four patients had nodules with significant growth over time. One patient with papillary thyroid carcinoma (PTC) on final pathology initially had a decreasing nodule size, and then a subsequent increase in the nodule size after 4.5 years. Thyroid nodules were surgically removed in 33\% with the final pathology showing a benign cytology in four patients, follicular adenoma in eight patients and PTC in two patients.

aJuanita K. Hodax and Kimberly Bowerman contributed equally to this work.

*Corresponding author: Jose Bernardo Quintos, MD, Department of Pediatrics, Division of Endocrinology and Diabetes, Hasbro Children's Hospital, 593 Eddy Street, Providence, RI 02903, USA, Phone: +401-444-5504, Fax: +401-793-8101,

E-mail: jbquintos@brown.edu

Juanita K. Hodax: Department of Pediatrics, Division of Endocrinology and Diabetes, Hasbro Children's Hospital, Providence, RI, USA. https://orcid.org/0000-0003-3441-3877 Kimberly Bowerman: The Warren Alpert Medical School of Brown University, Providence, RI, USA
Conclusions: The majority of patients with benign thyroid nodules had no significant increase in nodule size in the first year of follow-up, including one patient who was subsequently found to have PTC. We recommend follow-up US at 1 year after initial presentation in low-risk pediatric patients with benign thyroid nodule cytology.

Keywords: benign thyroid nodule; fine needle aspiration; follicular adenoma; papillary thyroid carcinoma; thyroid nodule.

\section{Introduction}

When a thyroid nodule is detected in an adult, recommendations for evaluation include ultrasound (US), thyroid function studies and fine needle aspiration (FNA) depending on the nodule size and US characteristics [1]. While the risk of malignancy is increased with certain nodule characteristics such as hypoechogenicity, microcalcifications, hypervascularity and size $>1 \mathrm{~cm}$ [2], the cytological assessment of the FNA is necessary to help determine if the nodule is malignant. The estimated false-negative rate of an FNA is between 1 and 10\% [3, 4]. Due to this falsenegative risk, the American Thyroid Association (ATA) recommends continued follow-up of a nodule with benign FNA with US re-evaluation in intervals ranging from $<12$ months to $>24$ months determined by risk stratification based upon initial US findings [1].

When a thyroid nodule is detected in a pediatric patient, evaluation and treatment is typically determined following the ATA guidelines for pediatric thyroid nodules [5]. Similar to adults, in a thyroid nodule with benign FNA results, repeat US evaluation of the nodule is recommended in 6-12 months [5]. However, data to support this recommendation is limited and is predominantly based on adult studies, despite well-characterized differences between thyroid nodules in adults and children. While the prevalence of thyroid nodules in children is only $0.2 \%-5 \%$, pediatric nodules have a much higher risk of malignancy compared to adults [6,7]. Additionally, there have been several studies that raise the question of whether pediatric and adult thyroid cancer 
should be treated as distinct diseases. While the nodule US characteristics predictive of malignancy are similar between adults and children [8], pediatric thyroid cancer is more commonly associated with lymph node metastasis, is typically well differentiated, and has different molecular abnormalities in comparison to adult thyroid cancer $[9,10]$.

There have been several studies in adults following the natural history of FNA-benign thyroid nodules to determine the optimal time interval for re-evaluation of benign thyroid nodules in adult patients [11-13]. One recently published study evaluated the follow-up strategy for benign nodules in pediatric patients and recommends individualizing the US follow-up interval based on nodule characteristics [14]. Given the epidemiologic and clinical differences between adult and pediatric thyroid nodules, additional studies in pediatric patients are needed to guide these decisions. In this study, we aimed to evaluate the natural history of FNA-benign thyroid nodules in pediatric patients, and to determine the optimal time interval for repeat US evaluation.

\section{Materials and methods}

This was a retrospective chart review of patients less than 19 years of age at the Rhode Island Hospital from 2003 to 2013. We searched all patients seen at the Rhode Island Hospital and the Hasbro Children's Hospital who were less than 19 years of age and had the International Classification of Diseases, Ninth Revision diagnosis code of thyroid nodule (code 241). We collected the demographic data, clinical history and exam, results of all thyroid US and FNA evaluations, treatment modalities including thyroidectomy, and final pathology results. US were performed at the Rhode Island Hospital or the Hasbro Children's Hospital and read by experienced radiologists, with the exception of two patients who had the initial US performed at an outside facility. Patients with single and multiple nodules were included. Patients presented between January 2003 and December 2013, and follow-up data were collected through December 2015. Patients with autonomously functioning thyroid nodules from this cohort were previously described [15]. The Rhode Island Hospital Institutional Review Board approved this study.

Medical records were reviewed and 156 patients were identified with one or more thyroid nodules confirmed by US diagnosed before the age of 19 years. One hundred and thirteen patients were excluded for the following reasons: autonomously functioning thyroid nodule (13 patients), Hashimoto's thyroiditis (12 patients), Graves' disease (three patients) or history of radiation therapy (one patient). Patients that did not have an FNA, or had FNA showing cystic contents only, atypical cells or concern for malignancy, were also excluded (84 patients). There were 43 patients remaining who had FNA results with benign pathology (Bethesda category II) who were included in the analysis. In patients with multiple nodules, FNA was performed on the largest nodule or on multiple nodules with each FNA showing benign pathology. Of these patients, 14 had thyroidectomy performed, with the final pathology from the surgical specimens showing follicular adenoma in eight patients, benign nodule in four patients and papillary thyroid carcinoma (PTC) in two patients. These results are detailed in Figure 1.

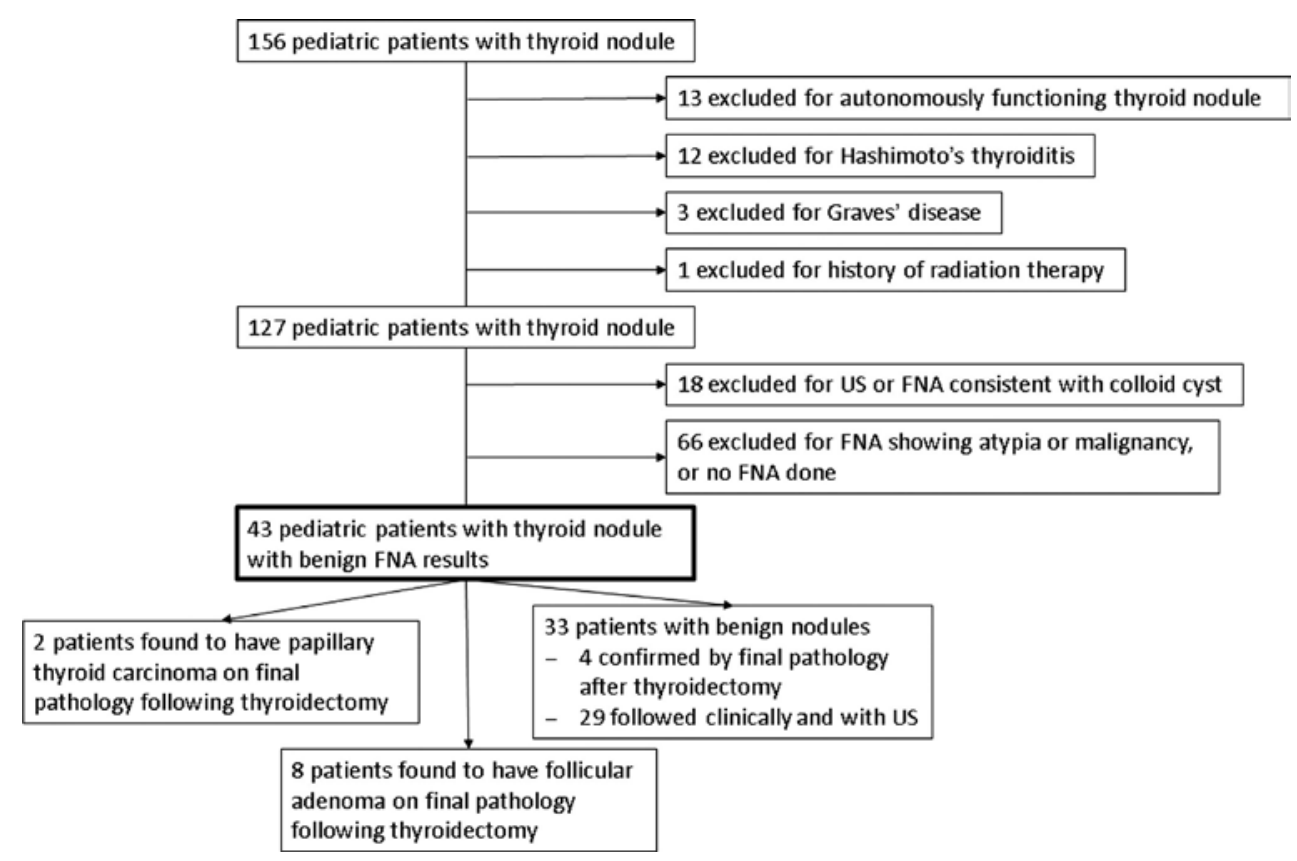

Figure 1: Chart review findings and exclusions. 


\section{Results}

Forty-three patients were identified with FNA-benign thyroid nodules. After follow-up examinations and surgical removal in some patients, two patients were found to have PTC and eight patients had follicular adenoma on the final pathology. Thirty-three patients continued to have the diagnosis of benign thyroid nodule at the last follow-up examination.

\section{Clinical characteristics}

The mean age of all patients with a thyroid nodule and benign FNA was 15.6 years at diagnosis; range 0.8-18.8 years. There was female predominance, with 39 females and four males. Thyroid-stimulating hormone levels were normal in all patients who had laboratory data available. Thyroid nodules were diagnosed incidentally on imaging for unrelated reasons (five patients), detected by healthcare providers (11 patients) or detected by family members (seven patients). Demographic data, laboratory values and clinical presentation are detailed in Table 1.

\section{Radiographic studies}

The mean nodule size determined by the initial US was $2.5 \mathrm{~cm}$; range $0.6-5.3 \mathrm{~cm}$. Laterality of thyroid nodules was 23 right, 16 left and two isthmus. Single nodules were found in 29 patients, whereas 12 patients had more than one thyroid nodule. The initial US showed the following characteristics: $9 \%$ calcifications, 33\% hyperemia, $28 \%$ hypoechoic nodules and 7\% lymphadenopathy. The prevalence of these characteristics was similar among patients who had a final diagnosis of benign thyroid nodule, follicular adenoma and PTC. Nodule size, laterality and US findings are detailed in Table 2.

\section{Fine needle aspiration results}

All patients included in the study had benign pathology on FNA. If the initial FNA was indeterminate, an FNA was repeated and showed benign pathology. Of the 43 patients included in the final analysis, none of the patients had abnormal FNA results as these patients were excluded from analysis. Three patients (7\%) had follow-up repeat FNA performed (excluding indeterminate results) with each of these showing benign pathology, and there has been no further US monitoring for these three patients to
Table 1: Clinical characteristics of all patients with thyroid nodules with benign cytology on initial FNA.

\begin{tabular}{|c|c|c|c|c|}
\hline & $\begin{array}{r}\text { All } \\
\text { patients }\end{array}$ & Benign & $\begin{array}{l}\text { Follicular } \\
\text { adenoma }\end{array}$ & PTC \\
\hline Number of patients & 43 & 33 & 8 & 2 \\
\hline \multicolumn{5}{|l|}{ Age at diagnosis, years } \\
\hline Average & 15.6 & 15.3 & 16.3 & 17 \\
\hline $0-5$ & $1(2 \%)$ & $1(3 \%)$ & $0(0 \%)$ & $0(0 \%)$ \\
\hline $6-10$ & $1(2 \%)$ & $1(3 \%)$ & $0(0 \%)$ & $0(0 \%)$ \\
\hline $11-15$ & $20(47 \%)$ & $16(48 \%)$ & $3(38 \%)$ & $1(50 \%)$ \\
\hline $16-18$ & $21(49 \%)$ & $15(45 \%)$ & $5(63 \%)$ & $1(50 \%)$ \\
\hline \multicolumn{5}{|l|}{ Gender } \\
\hline M & $4(9 \%)$ & $4(12 \%)$ & $0(0 \%)$ & $0(0 \%)$ \\
\hline $\mathrm{F}$ & $39(91 \%)$ & $29(88 \%)$ & $8(100 \%)$ & $2(100 \%)$ \\
\hline \multicolumn{5}{|l|}{ Race } \\
\hline White & $32(74 \%)$ & $23(70 \%)$ & $7(88 \%)$ & $2(100 \%)$ \\
\hline Black & $4(9 \%)$ & $4(12 \%)$ & $0(0 \%)$ & $0(0 \%)$ \\
\hline Other/not provided & $7(16 \%)$ & $6(18 \%)$ & $1(13 \%)$ & $0(0 \%)$ \\
\hline \multicolumn{5}{|l|}{$\mathrm{TSH}, \mathrm{mIU} / \mathrm{mL}$} \\
\hline Average & 1.37 & 1.33 & 1.62 & 0.78 \\
\hline Low $(<0.35)$ & $0(0 \%)$ & $0(0 \%)$ & $0(0 \%)$ & $0(0 \%)$ \\
\hline Normal $(0.35-5.5)$ & 35 (81\%) & $25(76 \%)$ & $8(100 \%)$ & $2(100 \%)$ \\
\hline High $(>5.5)$ & $0(0 \%)$ & $0(0 \%)$ & $0(0 \%)$ & $0(0 \%)$ \\
\hline Not available & $8(19 \%)$ & $8(24 \%)$ & $0(0 \%)$ & $0(0 \%)$ \\
\hline \multicolumn{5}{|l|}{ Mode of diagnosis } \\
\hline $\begin{array}{l}\text { Incidentally on } \\
\text { imaging }\end{array}$ & $5(12 \%)$ & $4(12 \%)$ & $1(13 \%)$ & $0(0 \%)$ \\
\hline $\begin{array}{l}\text { Palpated by } \\
\text { physician }\end{array}$ & $11(26 \%)$ & $9(27 \%)$ & $2(25 \%)$ & $0(0 \%)$ \\
\hline $\begin{array}{l}\text { Noticed by } \\
\text { patient/family }\end{array}$ & $7(16 \%)$ & $4(12 \%)$ & $2(25 \%)$ & $1(50 \%)$ \\
\hline Not documented & $20(47 \%)$ & $16(48 \%)$ & $3(38 \%)$ & $1(50 \%)$ \\
\hline
\end{tabular}

FNA, fine needle aspiration; PTC, papillary thyroid carcinoma; TSH, thyroid-stimulating hormone.

date. Fourteen patients had thyroidectomy or lobectomy performed, with the final pathology after surgical removal showing follicular adenoma in eight patients and PTC in two patients. This results in a $4.6 \%$ false-negative FNA rate for thyroid malignancy.

\section{Follow-up data}

Twenty-five patients had only one US, and then subsequently had surgery (10 patients) or were lost to follow-up or transferred care (15 patients). Repeat US was performed in 18 patients (42\%) at time intervals ranging from 1 month to 5.5 years, with an average interval of 15 months until the first follow-up US. The average length of follow-up was 28 months during the period of data collection. Four patients had nodules with significant 
Table 2: Initial ultrasound findings.

\begin{tabular}{|c|c|c|c|c|}
\hline & $\begin{array}{r}\text { All } \\
\text { patients }\end{array}$ & Benign & $\begin{array}{l}\text { Follicular } \\
\text { adenoma }\end{array}$ & PTC \\
\hline Number of patients & 43 & 33 & $8^{a}$ & 2 \\
\hline \multicolumn{5}{|c|}{ Size of the largest nodule (largest dimension) } \\
\hline Average, $\mathrm{cm}$ & 2.5 & 2.3 & 3.5 & 2.8 \\
\hline Range & $0.6-5.3$ & $0.6-4.7$ & $1.9-5.3$ & $2.5-3$ \\
\hline$<1 \mathrm{~cm}$ & $4(10 \%)$ & $4(13 \%)$ & $0(0 \%)$ & $0(0 \%)$ \\
\hline $1-1.9 \mathrm{~cm}$ & $11(28 \%)$ & $10(32 \%)$ & $1(17 \%)$ & $0(0 \%)$ \\
\hline $2-2.9 \mathrm{~cm}$ & $8(21 \%)$ & $7(23 \%)$ & $0(0 \%)$ & $1(50 \%)$ \\
\hline $3-3.9 \mathrm{~cm}$ & $11(28 \%)$ & $7(23 \%)$ & $3(50 \%)$ & $1(50 \%)$ \\
\hline$>4 \mathrm{~cm}$ & $5(13 \%)$ & $3(10 \%)$ & $2(33 \%)$ & $0(0 \%)$ \\
\hline \multicolumn{5}{|l|}{ Number of nodules } \\
\hline 1 & $29(71 \%)$ & $23(70 \%)$ & $6(100 \%)$ & $0(0 \%)$ \\
\hline 2 & 7 (17\%) & $6(18 \%)$ & $0(0 \%)$ & $1(50 \%)$ \\
\hline 3 & $2(5 \%)$ & $1(3 \%)$ & $0(0 \%)$ & $1(50 \%)$ \\
\hline 4 & $2(5 \%)$ & $2(6 \%)$ & $0(0 \%)$ & $0(0 \%)$ \\
\hline 5 & $1(2 \%)$ & $1(3 \%)$ & $0(0 \%)$ & $0(0 \%)$ \\
\hline \multicolumn{5}{|c|}{ Laterality (largest nodule) } \\
\hline Right & $23(56 \%)$ & $18(55 \%)$ & $3(50 \%)$ & $2(100 \%)$ \\
\hline Left & $16(39 \%)$ & $13(39 \%)$ & $3(50 \%)$ & $0(0 \%)$ \\
\hline Isthmus & $2(5 \%)$ & $2(6 \%)$ & $0(0 \%)$ & $0(0 \%)$ \\
\hline \multicolumn{5}{|l|}{ Cystic component } \\
\hline Yes & $27(66 \%)$ & $23(70 \%)$ & $3(50 \%)$ & $1(50 \%)$ \\
\hline No & $14(34 \%)$ & $10(30 \%)$ & $3(50 \%)$ & $1(50 \%)$ \\
\hline \multicolumn{5}{|l|}{ Calcifications } \\
\hline Yes & $4(10 \%)$ & $2(6 \%)$ & $1(17 \%)$ & $1(50 \%)$ \\
\hline No & $37(90 \%)$ & 31 (94\%) & $5(83 \%)$ & $1(50 \%)$ \\
\hline \multicolumn{5}{|l|}{ Hyperemia } \\
\hline Yes & $15(37 \%)$ & $12(36 \%)$ & $2(33 \%)$ & $1(50 \%)$ \\
\hline No & $26(63 \%)$ & $21(64 \%)$ & $4(67 \%)$ & $1(50 \%)$ \\
\hline \multicolumn{5}{|l|}{ Hypoechoic } \\
\hline Yes & $12(29 \%)$ & $11(33 \%)$ & $1(17 \%)$ & $0(0 \%)$ \\
\hline No & $29(71 \%)$ & $22(67 \%)$ & $5(83 \%)$ & $2(100 \%)$ \\
\hline \multicolumn{5}{|l|}{ Lymphadenopathy ${ }^{b}$} \\
\hline Yes & $3(7 \%)$ & $3(9 \%)$ & $0(0 \%)$ & $0(0 \%)$ \\
\hline No & $38(93 \%)$ & 30 (91\%) & $6(100 \%)$ & $2(100 \%)$ \\
\hline
\end{tabular}

${ }^{a}$ Complete ultrasound data not available for two patients with follicular adenoma. 'bymphadenopathy as found on ultrasound. PTC, papillary thyroid carcinoma.

growth over time ( $>20 \%$ increase in the largest diameter). Of the patients with follow-up US, six patients had development of new nodule characteristics on subsequent US (two nodules had new findings of hyperemia; one with hypoechogenicity; one with calcifications; one with a new cystic component; and one with new hypoechogenicity and cystic component). All of these nodules continue to have the diagnosis of benign thyroid nodule, although only one patient has had a repeat FNA and none of these patients had thyroidectomy. Twelve patients had no change in nodule characteristics. One patient with PTC on final pathology initially had a decreasing nodule size, and then a subsequent increase in the nodule size after 4.5 years. Details of nodule size on repeat US are shown in Figure 2. Follow-up and treatment data are detailed in Table 3.

\section{Treatment and final pathology}

Fourteen patients had a thyroid nodule removed by thyroidectomy or lobectomy. In four patients, final pathology showed benign thyroid tissue. Although FNA results were benign, these patients had thyroidectomy done due to large nodule size in one patient $(4.7 \times 2.5 \times 3.7 \mathrm{~cm})$, suspicious US findings in one patient (hyperemia, cystic and solid components) and patient preference in one patient. The reason for surgery was not documented in one patient. In eight patients, the final pathology showed follicular adenoma. Four of these patients had thyroidectomy due to increasing growth in thyroid nodule, though this growth was often monitored by the surgeon and was not documented in formal US reports. Reasons for thyroidectomy are detailed in Table 3.

In two patients, the final pathology showed PTC. One patient initially had a hemi-thyroidectomy due to compressive symptoms. The initial thyroid US showed a multilobulated, solid mass in the right lobe of the thyroid gland measuring $2.5 \times 2.4 \times 2.2 \mathrm{~cm}$ and with peripheral increased blood flow. There were also two small nodules within the left lobe of the thyroid gland that were $<1 \mathrm{~cm}$ in size. FNA was benign. The final pathology after right hemi-thyroidectomy showed an encapsulated follicular variant of PTC with oncocytic features and with foci of capsular invasion $(2.6 \mathrm{~cm})$. Completion left-hemithyroidectomy was subsequently done and showed two microscopic foci of PTC measuring $0.1 \mathrm{~cm}$ and $0.15 \mathrm{~cm}$. There was no lymphadenopathy. The patient was treated with radioactive iodine and has not had recurrence of PTC.

The second patient who had PTC on the final pathology had a thyroidectomy almost 5 years after her initial diagnosis of the thyroid nodule. The initial US showed multiple cysts and solid masses with a predominantly cystic nodule with a small solid component in the right lobe measuring $3 \times 2.5 \mathrm{~cm}$. There was also a large nodule on the left measuring $2.6 \times 1.8 \mathrm{~cm}$, with possible calcifications. FNA of both nodules were benign, and thyroid nodules were monitored by US once a year for 2 years, then with a 2.5-year interval until her next US. The US initially showed an unchanged size of the nodule, and then an increase in size with the largest nodule in the right lobe 


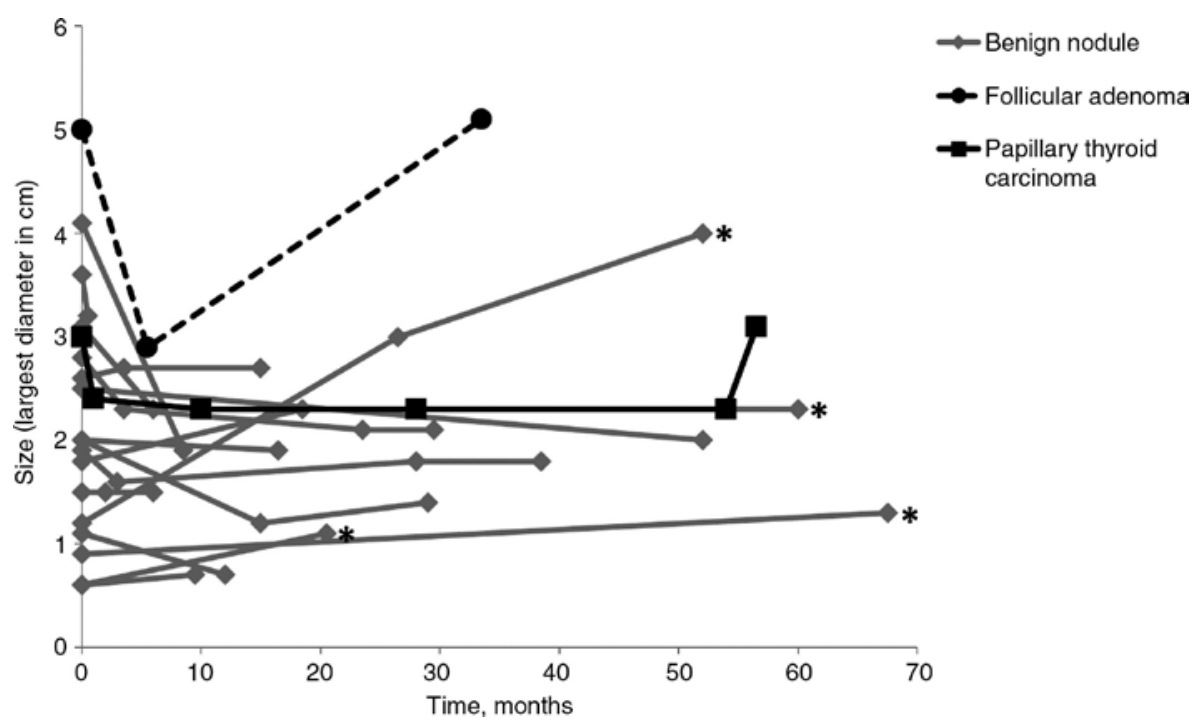

Figure 2: Nodule growth over time shown on follow-up ultrasounds.

Each line represents one patient with an FNA-benign thyroid nodule followed by ultrasound over time. Each point on the graph represents an ultrasound, showing the time in months between ultrasounds on the X-axis, and the change in size of the thyroid nodule on the $Y$-axis. The black line with square markers represents a patient with a final pathology of papillary thyroid carcinoma after having thyroidectomy. The black dashed line with circle markers represents a patient with a final pathology of follicular adenoma after having thyroidectomy. The gray lines with diamond markers are patients who continue to have the diagnosis of benign thyroid nodule. *Asterisks represent the patients that had a significant increase in the size of the thyroid nodule over time ( $>20 \%$ increase in the largest diameter).

Table 3: Follow-up data.

\begin{tabular}{lrrrr}
\hline \multicolumn{1}{l}{$\begin{array}{r}\text { All } \\
\text { patients }\end{array}$} & Benign & $\begin{array}{r}\text { Follicular } \\
\text { adenoma }\end{array}$ & PTC \\
\hline Number of patients & 43 & 33 & 8 & 2 \\
$\begin{array}{l}\text { Number of ultrasounds } \\
1\end{array}$ & $25(58 \%)$ & $17(52 \%)$ & $7(88 \%)$ & $1(50 \%)$ \\
2 & $9(21 \%)$ & $9(27 \%)$ & $0(0 \%)$ & $0(0 \%)$ \\
3 & $5(12 \%)$ & $4(12 \%)$ & $1(13 \%)$ & $0(0 \%)$ \\
4 & $3(7 \%)$ & $3(9 \%)$ & $0(0 \%)$ & $0(0 \%)$ \\
5 & $0(0 \%)$ & $0(0 \%)$ & $0(0 \%)$ & $0(0 \%)$ \\
6 & $1(2 \%)$ & $0(0 \%)$ & $0(0 \%)$ & $1(50 \%)$ \\
Number of FNAs & & & & \\
1 & $40(93 \%)$ & $30(91 \%)$ & $8(100 \%)$ & $2(100 \%)$ \\
2 & $3(7 \%)$ & $3(9 \%)$ & $0(0 \%)$ & $0(0 \%)$ \\
Thyroidectomy & & & & \\
Yes & $14(33 \%)$ & $4(12 \%)$ & $8(100 \%)$ & $2(100 \%)$ \\
No & $29(67 \%)$ & $29(88 \%)$ & $0(0 \%)$ & $0(0 \%)$ \\
Reason for thyroidectomy & & & \\
Concerning US & $2(14 \%)$ & $1(25 \%)$ & $1(13 \%)$ & $0(0 \%)$ \\
findings & & & & \\
Large nodule size & $3(21 \%)$ & $1(25 \%)$ & $2(25 \%)$ & $0(0 \%)$ \\
Nodule growth & $5(36 \%)$ & $0(0 \%)$ & $4(50 \%)$ & $1(50 \%)$ \\
$\begin{array}{l}\text { over time } \\
\text { Compressive }\end{array}$ & $2(14 \%)$ & $0(0 \%)$ & $1(13 \%)$ & $1(50 \%)$ \\
symptoms & $1(7 \%)$ & $1(25 \%)$ & $0(0 \%)$ & $0(0 \%)$ \\
$\begin{array}{l}\text { Patient choice } \\
\text { Not documented }\end{array}$ & $1(7 \%)$ & $1(25 \%)$ & $0(0 \%)$ & $0(0 \%)$ \\
\hline
\end{tabular}

FNA, fine needle aspiration; PTC, papillary thyroid carcinoma; US, ultrasound. measuring $2.7 \times 3.1 \times 3.1 \mathrm{~cm}$ (4.5 years after the initial US). There was no increase in calcifications, and no development of hyperemia, hypoechogenicity or lymphadenopathy. The patient had developed pain with swallowing, and thyroidectomy was performed. The final pathology showed the follicular variant of PTC in the left lobe, $1 \mathrm{~cm}$ in size with partial encapsulation and all margins free from tumor. Background nontumoral thyroid tissue showed predominantly multinodular adenomatous hyperplasia. She was subsequently treated with radioactive iodine without complication or recurrence.

\section{Discussion}

Current ATA guidelines for the management of thyroid nodules in pediatric patients recommend a follow-up US in 6-12 months for patients with a benign pathology on FNA, and subsequent US every 1-2 years [5]. Follow-up of FNA-benign thyroid nodules is necessary in pediatric patients due to the higher risk of malignancy in children compared to adults, and due to the possibility of falsenegative FNA results. However, data evaluating the frequency and timing of US follow-up in pediatric patients are limited, with only one recent publication addressing this question [14]. 
In our cohort, 18 patients (42\%) had a follow-up US performed. Of these, only four patients (22\% of those with follow-up US) had an increase in nodule size defined as a $>20 \%$ increase in the largest diameter. This is similar to the recent study of benign nodules in pediatric patients where they observed nodule growth at first US follow-up in $24 \%$ of nodules (median 11 months after benign FNA) and $36 \%$ showed growth at any time during follow-up (median 15.6 months) [14]. They identified that nodules with lower cystic content and nodules in multinodular glands had an increased likelihood of nodule growth, and recommend individualizing the timing of US follow-up based on these characteristics.

These results are similar to a large prospective study in adult patients, evaluating the natural history of benign thyroid nodules with yearly US for 5 years [12]. In this adult study, there was significant nodule growth in $15 \%$ of cases, and the majority of nodules did not change in size, or spontaneously decreased in size. There was a $0.3 \%$ false-negative FNA rate in this study, with only five patients eventually diagnosed with thyroid cancer. Among those patients, only two had an increase in nodule size over time [12]. In a large study of thyroid nodules in adults and adolescents as young as 14 years of age, six patients had an increasing nodule size over time and none of these patients were diagnosed with thyroid malignancy [16]. In another study of adults with thyroid nodules, the false-negative FNA rate was 4.2\% [13]. Patients who were eventually diagnosed with thyroid malignancy had thyroidectomy $>4$ years after their initial thyroid nodule diagnosis, despite yearly follow-up US. In our study, there was a $4.6 \%$ false-negative FNA rate for detecting malignancy, with two patients having a diagnosis of PTC after thyroidectomy despite benign FNA results. This is consistent with the previous literature $[3,4,13]$.

These adult studies conclude that the frequency of thyroid US follow-up can be decreased in adults, as yearly thyroid US did not improve outcomes or detection of malignancy in adult patients. This led to a change in the adult ATA guidelines in the 2015 revision which now recommends different US follow-up intervals of FNA-benign thyroid nodules by risk stratification based on US findings $(<12$ months for nodules with high-suspicion US pattern; 12-24 months for intermediate suspicion; $>24$ months for low suspicion) [1]. Previously, the recommendation had been to have a follow-up US evaluation every 6-18 months for all FNA-benign thyroid nodules [17].

Prior studies have found the following US features to be concerning for malignancy in pediatric patients: microcalcifications, hypoechoic pattern, increased intranodular vascularization, abnormal lymph node and irregular margins $[8,18-20]$. The ATA guidelines recommend FNA in nodules with these characteristics, regardless of nodule size [5]. Overall, there was a low frequency of these concerning US findings in our patient cohort. One patient that had a final diagnosis of PTC did have calcifications evident on US, and the other patient with PTC had a nodule with hyperemia and no other changes concerning for malignancy.

Limitations of the study include retrospective data collection, as patients were seen by several different providers leading to variability in evaluation and timing of follow-up. Overall, there are a small number of patients with complete follow-up data. Many patients were lost to follow-up or transferred care and may not have follow-up data available. There were also some patients who were initially evaluated and followed by an endocrine surgeon rather that a pediatric endocrinologist, and intra-office US may not have been documented in the available records for review. In addition, many patients continue to be followed by US and have not had thyroidectomy. These patients are currently thought to have benign nodules based on FNA results, but may have different pathology if nodules are surgically removed in the future.

Our observations based on these findings are that thyroid nodules with benign FNA results have limited growth over time, without significant increase in nodule size in the first year after diagnosis, and repeat US within 1 year have limited value and did not change the clinical course for the patients in our cohort. Due to the higher prevalence of malignancy in thyroid nodules in pediatric patients compared to adults [6], thyroid nodules in pediatric patients should be followed long term. This is also supported by one patient in our cohort who had an increase in nodule size 4.5 years after the diagnosis of thyroid nodule and was subsequently found to have PTC.

The current guidelines state that surgery should be considered for nodules with suspicious US findings, size $>4 \mathrm{~cm}$, or clinical concerns for malignancy [5], which is also supported by our data as many of the patients who had thyroidectomy or lobectomy shortly after their initial diagnosis of thyroid nodule were found to have follicular adenoma, or PTC in one patient.

\section{Conclusions}

The majority of patients with benign thyroid nodules did not have a significant increase in nodule size in the first year of follow-up, including one patient who was subsequently found to have PTC. In our cohort, US performed 
less than 1 year after the initial US did not provide additional diagnostic information or change clinical management. Therefore, we recommend the first follow-up US to be done 1 year after the initial presentation in low-risk pediatric patients with benign thyroid nodule cytology on FNA. Due to the higher rate of malignancy in pediatric patients and the possibility of false-negative FNA, thyroid nodules should continue to be monitored long term due to the possibility of malignancy developing over time. Increased nodule growth over time or change in US characteristics would be concerning for potential malignancy.

Author contributions: All the authors have accepted responsibility for the entire content of this submitted manuscript and approved submission.

Research funding: None declared.

Employment or leadership: None declared.

Honorarium: None declared.

Competing interests: The funding organization(s) played no role in the study design; in the collection, analysis, and interpretation of data; in the writing of the report; or in the decision to submit the report for publication.

Ethical statement: The study was approved by the Rhode Island Hospital Institutional Review Board.

\section{References}

1. Haugen BR, Alexander EK, Bible KC, Doherty GM, Mandel SJ, et al. 2015 American Thyroid Association Management Guidelines for Adult Patients with Thyroid Nodules and Differentiated Thyroid Cancer: The American Thyroid Association Guidelines Task Force on Thyroid Nodules and Differentiated Thyroid Cancer. Thyroid 2016;26:1-133.

2. Papini E, Guglielmi R, Bianchini A, Crescenzi A, Taccogna S, et al. Risk of malignancy in nonpalpable thyroid nodules: predictive value of ultrasound and color-Doppler features. J Clin Endocrinol Metab 2002;87:1941-6.

3. Carmeci C, Jeffrey RB, McDougall IR, Nowels KW, Weigel RJ. Ultrasound guided fine-needle aspiration biopsy of thyroid masses. Thyroid 1998;8:283-9.

4. Wang CC, Friedman L, Kennedy GC, Wang H, Kebebew E, et al. A large multicenter correlation study of thyroid nodule cytopathology and histopathology. Thyroid 2011;21:243-51.

5. Francis GL, Waguespack SG, Bauer AJ, Angelos P, Benvenga S, et al. Management Guidelines for Children with Thyroid Nodules and Differentiated Thyroid Cancer. Thyroid 2015;25:716-59.
6. Gupta A, Ly S, Castroneves LA, Frates MC, Benson CB, et al. A standardized assessment of thyroid nodules in children confirms higher cancer prevalence than in adults. J Clin Endocrinol Metab 2013;98:3238-45.

7. Niedziela M. Thyroid nodules. Best Pract Res Clin Endocrinol Metab 2014;28:245-77.

8. Mussa A, De Andrea M, Motta M, Mormile A, Palestini N, et al. Predictors of malignancy in children with thyroid nodules. J Pediatr 2015;167:886-92.

9. Yamashita S, Saenko V. Mechanisms of disease: molecular genetics of childhood thyroid cancers. Nat Clin Pract Endocrinol Metab 2007;3:422-9.

10. Rivkees SA, Mazzaferri EL, Verburg FA, Reiners C, Luster M, et al. The treatment of differentiated thyroid cancer in children: emphasis on surgical approach and radioactive iodine therapy. Endocr Rev 2011;32:798-826.

11. Nou E, Kwong N, Alexander LK, Cibas ES, Marqusee E, et al. Determination of the optimal time interval for repeat evaluation after a benign thyroid nodule aspiration. J Clin Endocrinol Metab 2014;99:510-6.

12. Durante C, Costante G, Lucisano G, Bruno R, Meringolo D, et al. The natural history of benign thyroid nodules. J Am Med Assoc 2015;313:926-35.

13. Ajmal S, Rapoport S, Ramirez Batlle H, Mazzaglia PJ. The natural history of the benign thyroid nodule: what is the appropriate follow-up strategy? J Am Coll Surg 2015;220:987-92.

14. Cherella CE, Feldman HA, Hollowell M, Richman DM, Cibas ES, et al. Natural history and outcomes of cytologically benign thyroid nodules in children. J Clin Endocrinol Metab 2018;103:3557-65.

15. Hodax JK, Reinert SE, Quintos JB. Autonomously functioning thyroid nodules in patients $<21$ years of age: the Rhode Island Hospital experience from 2003-2013. Endocr Pract 2016;22:328-37.

16. Orlandi A, Puscar A, Capriata E, Fideleff H. Repeated fine-needle aspiration of the thyroid in benign nodular thyroid disease: critical evaluation of long-term follow-up. Thyroid 2005;15:274-8.

17. American Thyroid Association (ATA) Guidelines Taskforce on Thyroid Nodules and Differentiated Thyroid Cancer, Cooper DS, Doherty GM, Haugen BR, Kloos RT, et al. Revised American Thyroid Association management guidelines for patients with thyroid nodules and differentiated thyroid cancer. Thyroid 2009;19:1167-214.

18. Lyshchik A, Drozd V, Demidchik Y, Reiners C. Diagnosis of thyroid cancer in children: value of gray-scale and power Doppler US. Radiology 2005;235:604-13.

19. Martinez-Rios C, Daneman A, Bajno L, van der Kaay DC, Moineddin R, et al. Utility of adult-based ultrasound malignancy risk stratifications in pediatric thyroid nodules. Pediatr Radiol 2018;48:74-84.

20. Koltin D, O'Gorman CS, Murphy A, Ngan B, Daneman A, et al. Pediatric thyroid nodules: ultrasonographic characteristics and inter-observer variability in prediction of malignancy. J Pediatr Endocrinol Metab 2016;29:789-94. 